\title{
Disgenesia gonadal pura: Síndrome de Swyer-James. Presentación de un caso y revisión de la literatura
}

\author{
Juan Diego Villegas*; Rodrigo Cuevas M.**; Germán Barón***
}

\begin{abstract}
RESUMEN: El síndrome de Swyer-James es un desorden de los cromosomas sexuales y la diferenciación sexual caracterizado por una disgenesia gonadal pura $46 \mathrm{XY}$ en un individuo fenotípicamente femenino con amenorrea primaria. El presente artículo pretende reportar un caso diagnosticado y manejado en la Unidad de Investigación clínica en Reproducción Humana (UICRH) del Hospital Infantil Universitario Lorencita Villegas de Santos, además de revisar la literatura reciente acerca de este trastorno poco frecuente.
\end{abstract}

PALABRAS CLAVES: Síndrome de Swyer, disgenesia gonadal, amenorrea primaria.

SUMMARY: The Swyer-James Syndrome is a sexual chromosomes disorder with alteration of the sexual differentiation, caracterized by a pure gonadal dysgenesis in a patient fenotipically female and with primary amenorrhea. This articule reports a case diagnosed and treated at the Unit of Clinical Investigation in Human Reproduction (UICRH) from the Hospital Infantil Universitario Lorencita Villegas de Santos and beside reviews the literature about this unfrecuent syndrome.

KEY WORDS: Swyer Syndrome, Gonadal dysgenesis, Primary amenorrhea.

El sindrome de Swyer-James es un desorden de los cromosomas sexuales y la diferenciación sexual caracterizado por una disgenesia gonadal pura $46 \mathrm{XY}$ en un individuo fenotípicamente femenino con amenorrea primaria.

En 1955, GL. Swyer documentó y publicó los primeros dos casos de disgenesia gonadal pura en el British Medical Journal en un artículo titulado "Male pseudohermaphroditism: A hitherto undescribed form" (Pseudohermafroditismo masculino: Una forma hasta ahora no descrita). Ambas pacientes eran fenotípicamente femeninas y consultaban por amenorrea. Ambas eran altas, de proporciones antropométricas eunucoides y con muy pobre desarrollo mamario. Los vellos axilar y púbico estaban presentes y en cantidades y distribución normales. Swyer no consideró necesario la gonadectomía en estas pacientes (1)

A propósito de la presentación de un caso, evaluado y manejado en la Unidad de Investigación Clínica en Reproducción Humana del Hospital Infantil Lorencita Villegas de Santos, se pretende aquí revisar la diferenciación sexual genética y embriológica normal y las carac-

\footnotetext{
* Residente III año HILVS

** Instructor UICRH-HILVS

*** Jefe UICRH-HILVS
}

terísticas clínicas con el enfoque terapéutico de este cuadro poco frecuente.

\section{Reporte de un caso}

Se trata de una paciente de 36 años, soltera, natural de Santafé de Bogotá, que consultó por un cuadro de amenorrea primaria. La menarquia fue inducida a los 20 años con compuestos estrógeno-progestacionales los que recibía de manera cíclica desde entonces. Es la tercera de seis hijos (4 varones y dos mujeres). La hermana mayor presenta parálisis cerebral; el resto de los hermanos son sanos. No hay disturbios evidentes en la función ovárica de la madre y hermanas. Presenta además hipotiroidismo primario de origen autoinmune demostrado por la presencia anticuerpos antimicrosomales (1:25600), manejado con suplencia de tiroxina desde hace 4 años. También se diagnosticó riñón en herradura por medio de urografía excretora.

Al examen físico se encuentra paciente con peso de 63 $\mathrm{Kg}$, talla de $1.54 \mathrm{mts}$, envergadura $1.68 \mathrm{mts}$. Braquicefalia, puente nasal angosto. Hendiduras palpebrales normales, filtro nasal normal. Cuello corto sin masas. Senos con Tanner III. Vello axilar escaso. Examen cardiopulmonar y abdominal normal. Genitales externos femeninos con vello ginecoide Tanner V. Himen íntegro. Al tacto rectal se palpa útero de características normales. Los anexos no son palpables. Cubitus valgus, clinodactilia del 3 dedo bilateral. Manos grandes. 
Tiene cariotipo de octubre/ 88 que mostraba una constitución 46XY. El mismo complemento cromosómico se encontró en segundo cariotipo de mayo/89.

Trae biopsia gonadal (agosto/89) que muestra bandeleta fibrosa bilateral.

Dentro de su valoración se le solicitaron anticuerpos antinucleares que fueron no reactivos. Tiene FSH en $30.55 \mathrm{mUI} / \mathrm{ml}$., LH en $13.07 \mathrm{mUI} / \mathrm{ml}$ y testosterona total menor de $0.15 \mathrm{ng} / \mathrm{ml}$.

Se realizó laparotomía en enero de 1997 encontrándose útero de $7 \times 4 \times 4 \mathrm{~cm}$ y bandeleta fibrosa de $3 \times 2 \mathrm{~cm}$. en fosita ovárica izquierda, sin otros hallazgos importantes. Fosita ovárica derecha libre. Se practicó gonadectomía y la anatomía patológica mostró tejido fibroso.

La paciente se encuentra actualmente en control con terapia de reemplazo hormonal. Se envió a valoración y apoyo psicológico.

\section{Genética y embriología de la diferenciación sexual}

La determinación y diferenciación sexual normal se reaiiza en forma progresiva durante el período de desarrollo embrionario e implica la siguiente secuencia de eventos:

1. Diferenciación cromosómica: Se produce en el momento de la fecundación. Es responsable del sexo genético o genotipo del individuo.

2. Diferenciación gonadal: Se produce en los primeros 58 días de vida intrauterina. Depende de la dotación genética del individuo y es responsable del sexo gonadal.

3. Diferenciación somática o genital: Se produce entre el segundo y el séptimo mes de vida intrauterina. Depende de la secreción hormonal individual de cada sexo e incluye la diferenciación de los genitales internos y externos y del sistema nervioso central. El sexo somático se refuerza en la pubertad con la aparición de los caracteres sexúales secundarios y determinación del sexo fenotípico.

La interacción adecuada entre cada uno de estos eventos determina la correspondencia adecuada entre ellos y depende de múltiples factores (2-3).

Tanto los cromosomas sexuales $\mathrm{X}$ y $\mathrm{Y}$ como los autosomas contienen sitios que deben mantenerse intactos para el desarrollo sexual normal. El conocimiento de la localización de estos loci es muy importante para la interpretación de los desórdenes asociados a sus alteraciones y además, porque pueden permitir el aislamiento de las proteínas responsables de la diferenciación sexual (4-5).

\section{Factor determinante testicular (TDF)}

En la década de los sesentas, se asumía que las determinantes testiculares mayores (ahora llamadas TDF) se localizaban en el brazo corto del cromosoma Y, basados en la observación de que individuos con cargas cromosómicas $46 \mathrm{XY}$ y deleciones del brazo largo del cromosoma $Y$ tienen apariencia femenina. Mas tarde, la porción distal del cromosoma Y se descartó como portadora del TDF ante la evidencia de pacientes con únicamente anillos de $\mathrm{Y}$ y fenotipo masculino (6-7).

Se postuló entonces la posibilidad de la existencia de una zona pareada entre los brazos cortos de los cromosomas X y $\mathrm{Y}$ en la expresión de los genes de determinación sexual. Sin embargo, la presunción de su expresión pseudoautosómica no permitiría pensar que pudieran contener genes de determinación sexual (8).

Localizar en últimas la ubicación exacta del TDF requirió tecnología avanzada de biología molecular (y en realidad aún no es claro que secuencia corresponde al TDF ni su ubicación exacta). Al final, la secuenciación genética utilizando DNA clonado permitió localizarlo en una porción relativamente distal del brazo corto del cromosoma Y, muy cerca de la secuencia DXY S5 (secuencia íntimamente relacionada con la presencia de testículo).

En la siguiente gráfica se muestra la localización mas probable del TDF en el brazo corto del cromosoma Y $(6,9-12)$.

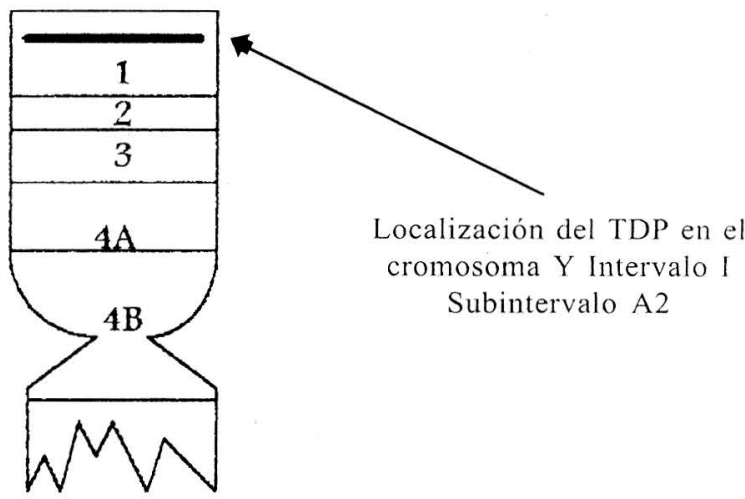

TDF, dedos de Zinc del Y (ZFY), región Y determinante del sexo (SRY) y antígeno HY

El TDF es un gen o porción de un gen que, en últimas, determina el desarrollo testicular. En un tiempo se pensó que el TDF eran un solo gen localizado en un punto cromosómico específico. Sinembargo, los estudios actuales han demostrado que se tratan de varios sitios localizados todos muy cerca unos de otros, con un patrón filogenético similar y, en últimas, todos en el intervalo 1 del cromosoma $\mathrm{Y}$ como ya se dijo.

Los llamados dedos de Zinc del Y, son proteínas que se unen a los ácidos nucleicos en una forma específica de secuencia y actúan regulando la transcripción de los TDF. Poseen una porción amino terminal ácida con $25 \%$ de residuos de ácido glutámico o aspártico. No es claro, pero aparentemente se trata de 13 dominios localizados principalmente en la porción carboxilo terminal $(6,13)$.

El HYA es una secuencia envuelta en el reconocimiento e interacción de célula a célula que tiene una correlación invariable con la presencia de testículos y, mas específicamente, con la espermatogénesis. Ultimamente se ha visto la utilidad pronóstica del estudio del HYA y la predisposición al desarrollo de neoplasias en las disgenesias gonadales XY. Aparentemente el HYA no depende de la presencia de células germinales. Su expresión tiene un perfil muy preciso, controlado en tiempo y espacio que se relaciona bien con la diferenciación testicular. 
La SRY es el gen mas prometedor para ser el TDF. Es una secuencia de DNA poco monótona localizada cercanamente a la región seudoautosómica sexual del cromosoma $Y$, aún mas cerca que los dedos de zinc, que tiene una función muy importante en la caracterización y expresión de los estados de seudohermafroditismo y sex reversal. El $S R Y$ parece controlar el inicio de la cascada de la expresión génica en la diferenciación genética y su transcripción cesa rápidamente después de la formación de los cordones testiculares $(6,14-15)$.

\section{Genes en el brazo largo del cromosoma $Y$}

El brazo largo del cromosoma $\mathrm{Y}$ consiste en una secuencia de DNA altamente repetitiva, responsable de las características de éste a la inmunofluorescencia.

Al parecer, contiene factores que tienen un efecto positivo sobre la talla y el tamaño de los dientes. Hay secuencias responsables en él de la espermatogénesis, principalmente las relacionadas con el HYA. Además, algunas deleciones de $\mathrm{Yq}$ tienen relación con la diferenciación neoplásica de las gónadas. Las características de las gónadas y del fenotipo también están relacionadas principalmente con el TDF.

Las alteraciones en uno o varios de los componentes del TDF se ven expresadas en las alteraciones de la diferenciación gonadal, testicular, total o parcial y pueden estar relacionadas, en algunos casos con las secuencias específicas de los genes del cromosoma largo del cromosoma $Y(3,6,10,16)$.

\section{Desarrollo gonadal}

La ausencia del cromosoma Y causa sobre la gónada indiferenciada su desarrollo como ovario. La humana es la única especie que no es fértil en presencia de la monosomía de X. Se cree que en los casos de caritipos $45 \mathrm{X}$ el problema no incluye falla gonadal sino más bien aumento de la atresia de las células germinales. El segundo cromosoma $\mathrm{X}$ es responsable del mantenimiento ovárico y de sus.folículos, más que de la diferenciación ovárica. Además, las regiones cromosómicas destinadas al desarrollo ovárico integral son locus autosómicos.

La diferenciación testicular se ha considerado siempre como gobernada por un gen único -o por varios loci(TDF) localizado en el sitio ya mencionado del cromosoma Y. Sinembargo, las extensas homologías entre los genes de los cromosomas X y $\mathrm{Y}$ han hecho postular la teoría de que el cromosoma $Y$ evolucionó a partir del cromosoma $X$. Esta teoría da fuerza a la hipótesis de que existan algunas determinantes gonadales idénticas tanto en el $\mathrm{X}$ como en el Y. Si esto es cierto, la determinación del sexo puede ser también controlada en parte por la llamada inactivación del $X$, donde en el hombre hay dos veces mas de producción a partir de este gen debido a que el cromosoma Y no está inactivado. En otras palabras, en la mujer (con carga cromosómica XX), la pareación del X produce inactivación del otro $\mathrm{X}$ y no producción de sustancias inhibitorias de las estructuras Müllerianas. Por el contrario, en los hombres con carotipo XY normal, la inactivación del X no se produce y la diferenciación gonadal es masculina. Inclusive, puede hasta pensarse que las determinantes gonadales humanas sean regulatorias y algunas regiones cromosómicas autosómicas pueden determinar y ser esenciales para la expresión de los genes de los cromosomas sexuales y, por consiguiente, de la diferenciación sexual $(3,6,8)$.

\section{Desarrollo embriológico de los conductos genitales}

Si bien el sexo del producto está genéticamente determinado desde el momento de la fecundación, las características morfológicas femeninas y masculinas sólo se adquieren después de la 7 - 8 semana de desarrollo. Los embriones, tanto femeninos como masculinos, tienen inicialmente 2 pares de conductos genitales: los mesonéfricos y los paramesonéfricos (Müller). La diferenciación genital y de los conductos ocurre una vez el desarrollo gonadal se ha establecido.

El conducto Mülleriano aparece como una invaginación longitudinal del epitelio celómico en la cara antero-lateral, sobre el pliegue urogenital, aproximadamente en el día 37 luego de la fecundación. En sentido craneal, el paramesonefros desemboca en la cavidad celómica. En la línea media, se pone en contacto íntimo con el conducto contralateral.

En un principio, los dos conductos de Müller están separados por un tabique, pero después se fusionan formando el conducto uterino. El extremo caudal de los conductos fusionados se proyecta hacia la pared posterior del seno urogenital donde da forma al tubérculo paramesonéfrico -de Müller-.

Los conductos de Wolff y Müller coexisten temporalmente en todos los embriones durante el período ambisexual de desarrollo antes de la semana 8. Posteriormente, sólo uno de estos sistemas se desarrolla y persiste normalmente, dando origen a estructuras especiales propias de cada sexo. El otro desaparece durante el tercer mes de desarrollo, a excepción de algunos vestigios no funcionantes.

La diferenciación sexual está influida directamente por el control hormonal dependiente de la carga cromosómica y de la interacción de los loci en los cromosomas sexuales y, tal vez, autosómicos. Los factores críticos que determinan cual de los dos conductos progresa o desaparece son secretados por la gónada y son:

-Hormona antimülleriana (AMH) y

-Testosterona.

La AMH es una hormona glucoproteica codificada por el cromosoma 19 y secretada por las células de Sertoli poco después de la diferenciación testicular, y es la responsable de la regresión de los conductos de Müller en la semana 8. En ausencia de AMH, el feto desarrolla genitales internos femeninos. Este desarrollo está condicionado por el desarrollo previo de los conductos mesonéfricos y por ende al del sistema renal. Es esta la causa de la asociación entre las anormalidades urinarias y genitales.

La testosterona, secretada por las células de Leydig, mantiene el desarrollo del conducto de Wolff ipsilateral y se encarga de la virilización del seno urogenital. El siguiente gráfico resume los conceptos mencionados atrás. 


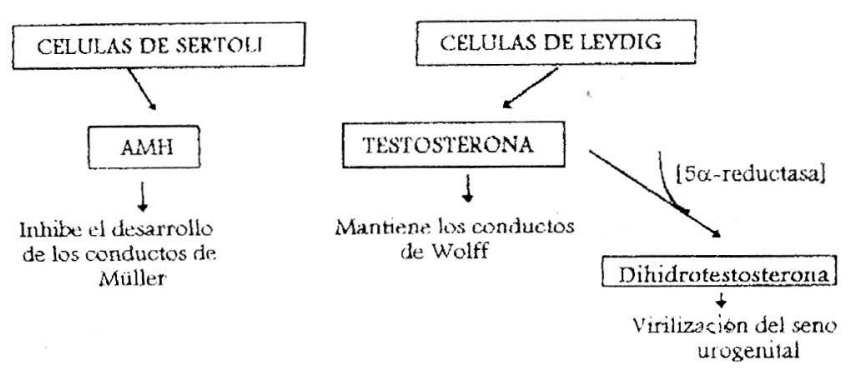

Los genitales externos poseen una tendencia intrínseca a la feminización en ausencia de cromosoma $Y$ y testículo secretante; la falta de AMH permite la continuidad de los conductos de Müller y así el desarrollo de trompas, útero y tercio superior de la vagina.

En ausencia de testosterona, el sistema mesonéfrico regresa y los estrógenos inducen la diferenciación de los genitales externos femeninos a partir del seno urogenital.

Entonces, el desarrollo de los conductos paramesonéfricos tiene lugar en presencia de ovarios o en ausencia de gónadas funcionantes.

Las trompas de Falopio, el útero y el tercio superior de la vagina se forman de la fusión de los conductos de Müller en la semana 10 de gestación. Bajo el epitelio descansa tejido mesenquimal que da origen al estroma uterino y al miometrio. En la semana 20 la mucosa uterina se diferencia completamente originando el endometrio (17-21).

\section{Síndrome de Swyer - James}

El sindrome de disgenesia gonadal pura XY (de Swyer-James), como ya se dijo, fue descrito por primera vez en la literatura en 1955. Se trata de un trastorno poco frecuente en el cual pacientes fenotípicamente femeninas presentan un cariotipo XY y ausencia total de tejido gonadal funcionante ("streak gonad") (1).

En la literatura desde 1955 hasta 1994, según la revisión publicada por los doctores Guidozzi, Ball y Spurdle en el Obstetrical and Gynecological Survey, sólo hay reportados 62 casos de pacientes con este trastorno. De ese número sólo 39 cumplen los criterios completos para el diagnóstico (cariotipo XY, sin ambigüedad de los genitales externos, biopsia gonadal característica de "streak gonad" y niveles de testosterona normales para la mujer) (22).

Característicamente, el cuadro se presenta con pacientes fenotípicamente femeninas normales que consultan por amenorrea y ausencia o muy pobre desarrollo de los caracteres sexuales secundarios. Las características fenotípicas muestran características eunucoides pero sin alteraciones evidentes de los genitales externos. Los genitales internos están presentes, pobremente desarrollados y con la presencia de las bandas fibrosas bilaterales que ocupan el espacio de las gónadas. Hay hallazgos de laboratorio de hipogonadismo hipergonadotrópico. Normalmente los hallazgos de los demás estudios y mediciones hormonales están dentro de los limites normales para la mujer (PRL, TSH, Cortisol, testosterona), menos el estradiol que tiende a estar normal o bajo (22).
La etiología de este trastorno persiste aún no aclarado. Probablemente se deba a cambios moleculares en la expresión del desarrollo gonadal de los cromosomas sexuales (22-23).

Se han planteado varias hipótesis acerca de los factores que determinan la aparición de esta patología. Puede deberse a una alteración en la sincronía de los eventos que finalmente se reflejan en la diferenciación de la gónada ambisexual alrededor de la semana 6-8 de gestación. El TDF debe expresarse sincrónicamente en el momento en el que aparece por primera vez dismorfismo sexual histológico en la gónada en desarrollo. Puede existir en estas pacientes una alteración en acople en el tiempo de estos eventos y presentarse una no involución de las estructuras responsables del desarrollo genital femenino a pesar de existir carga genética XY y TDF que, luego de que no actúa en el momento preciso, ya no puede ejercer sus funciones. Esta hipótesis fue propuesta por Burgoyne en 1989 pero nunca se corroboró con estudios posteriores en la literatura (22).

La etiología mas probable de éste trastorno es la alteración molecular de la expresión del TDF. En un gran porcentaje de las pacientes estudiadas por este trastorno, aunque no en todas, se han podido comprobar mutaciones en el SRY. En las demás tal vez haya alteraciones del promotor del SRY o trastornos intrínsecos del SRY que no se han detectado (22-23).

Otra posibilidad en la etiología de este síndrome es que aún no se hayan terminado de tipificar otros genes que sean responsables de la determinación sexual, tanto sexuales como autonómicos, que sean responsables, cuando están alterados, de la aparición de esta entidad (6-7, $11,22)$.

Lo único claro en la disgenesia gonadal pura hasta ahora es que su etiología sigue siendo un misterio y que sólo hipótesis han intentado revelar su génesis.

La malignización de la gónada fibrosa ocurre entre 10-30\% de las pacientes. Entonces está indicada claramente la laparotomía o laparoscopia y la gonadectomía en las pacientes luego del diagnóstico pues la malignización del tejido puede ocurrir en cualquier momento, inclusive en la infancia.. El gonadoblastoma ocupa el $75 \%$ de los tumores desarrollados a partir de la gónada $(22,24-25)$.

Hay reportado en la literatura la invasión intestinal de un disgerminoma surgido a partir de la gónada de una paciente con Síndrome de Swyer (26).

El tratamiento de esta paciente, además de la gonadectomía como ya se dijo, incluye una valoración y apoyo sociológico prolongado. Las pacientes deben seguir siendo manejadas como mujeres, a pesar de que la fertilidad no exista en lo absoluto. Debe darse suplencia hormonal en la forma usual y realizarse seguimiento paraclínico similar que en la paciente menopáusica. Debe explicársele claramente a la paciente su condición, su pronóstico y la necesidad y validez del tratamiento. La vida sexual debe ser normal y no debe haber alteraciones ni en el deseo ni en la satisfacción sexual ya que los órganos genitales femeninos tanto internos como externos están presentes y son normales $(2,22)$. 


\section{BIBLIOGRAFIA}

1. Swyer G1. Make Pseudihermafroditism: A hitherto undescribed form. B Med J 1955; 2: 709.

2. Sperof $L$ et al. Embriologic development of the genital tract en Clinical gynecologycal endocrinology. Sexta edición: 110.

3. Steinberger E, Odell WD. Genetics, anatomy, fetal endocrinology en DeGroot's textbook of Endocrinology Williams and Wilkins 1985; 1801.

4. Smith LH, Samy AH et al. Fisiopatología de Smith-Thier. Segunda edición. Editorial panamericana $1989 ; 450$.

5. Lewin B. Genes V. Ox ford University Press. 5th edition. 1994; 1110.

6. Wachtel SS. The genetics of intersexuality: clinical and theoretic perspectives. Obs Gyn. 1979; 54(6): 671 .

7. Hawkins R. Testis determining factor and Y-linked sex reversal. Current Opinion in Genetics and Development. 1991; 1: 30-33.

8. Pritchard CA, Goodfellow PJ. Mapping the limits of the human pseudoautosomal region and a candidate for the male determining gene. Nature 1987; 328: 273.

9. Tho SP, Layman LC et al. Absence of the testicular determining factor gene SRY in XX true hermaphrodites and presence of this locun in most subjects with gonadal dysgenesis caused by $Y$ aneuplody. Am J Obstet Gynecol 1992; 167: 1794.

10. Wolf $\mathrm{U}$, The molecular genetics of human sex determination. $J \mathrm{~mol}$ Med 1995; 73: 325.

11. Schafer AJ. Sex determination and its pathology in man. Adv Genet 1995; 33: 275 .

12. Lamb DJ. Genes involved in testicular development and function. World J Urol 1995; 13: 277.

13. Palmer MS. Sinclair AH. Genetic evidence that $\mathrm{ZFY}$ is not the testis determining factor. Nature 1989; 342: 937.

14. Berta P. Hawkins JR. Genetic evidence equating SRY and the testis determining factor. Nature 1990; 348: 448.
15. Behzadian MA, Tho $S$ et al. The presence of the testicular determining sequence, SRY, in 46XY females with gonadal dysgenesis. Am J Obstet Gynecol 1991; 165: 1887.

16. Ferguson-Smith MA. Gens on the $X$ and $Y$ chromosomes controlling sex. BMJ. 1988; 297: 635 .

17. Langman J. Desarrollo del aparato urogenital en Embriología médica. Cuarta edición. Editorial Panamericana 1989; 235.

18. Rock J. Surgery for anomalies of the müllerian ducts en Te Linde's operative Gynecology. Séptima edición: 603.

19. Markham SM, Waterhouse T. Structural anomalies of the reproductive tract. Curr Opin Obstet Gynecol. 1992; 4(6): 867.

20. Forstner R, Hricak H. Congenital malformations of uterus and vagina. Radiologe. 1994; 34(7): 397.

21. Kim HR, Laufer MR. Developmental abnormalities of the femmale reproductive tract. Curr Opin Obstet Gynecol. 1994; 6(6): 518.

22. Guidozzi F, Ball J et al. 46 XY pure gonadal dysgenesis (Swyer-james syndrome)- $Y$ or $Y$ not? : A review.

23. Hines RS. Tho SP. A novel mutation in the sex determining Region on Y (SRY) Gene as etiology of familial Swyer Syndrome. Fifty second anual meeting of the American Society for reproductive medicine. O 086. Nov 1996.

24. Wilson $\mathrm{E}$, Vuitch $\mathrm{F}$ et al. Laparoscopic removal of dysgenetic gonads containing a gonadoblastoma in a patient with Swyer syndrome. Obstet Gynecol 1992; 79: 842

25. Ramani $P, Y$ eung $C K$ et al. Testicular intratubular germ cell neoplasia in children and adolescents with intersex. Am J Surg Pathol 1993; 17: 1124.

26. Parker $M$, Barnhill $D$ et al. Intestinal invasion by a dysgerminoma in a patient with Swyer syndrome. Obstet Gynecol 1992; 80: 567. 